\title{
The Influence of Aesthetic Education on the Quality Education of Science and Technology University Students
}

\author{
Yao Shi \\ China Jiliang University \\ Academy of Marxism \\ Zhejiang, Hangzhou, China \\ E-mail:1107045541@qq.com
}

\begin{abstract}
In the education of science and technology university students in China, the function of aesthetic education has been neglected to some extent. Based on the author's internship experience and survey in a School of Art of a science and technology university, the author proposes the following ways to improve aesthetic education in science and technology universities. First, it is necessary to set up an aesthetic education course in the science and technology university, and at least one such course should be set up. Second, aesthetic education should be integrated into the teaching of various other subjects to improve the level of aesthetic education imperceptibly. Finally, a good campus culture and art environment should be created through humanities and arts profession, societies, clubs, etc.
\end{abstract}

Keywords-Aesthetic education; Aesthetic quality; Quality education; Science and technology universities

\section{AESTHETIC EDUCATION AND QUALITY EDUCATION}

If one looks into China's historical records, one can find that there are snippets written records on aesthetic education during the Spring and Autumn Period. Therefore, it is clear that in the long river of human development, aesthetic education can be said to be time-honoured. Usually, we will listen to some soothing music and songs to relax our mood, or read some books that are motivating when we are in the nadir of life, in order to achieve the purpose of stimulating ourselves, which allow us to be an appreciator to taste life through art, and cultivate our mind. Aesthetic education can cultivate our ability to cultivate the mind, but at the same time it plays a more powerful role in promoting our all-round development. We acquire the perfect ideal personality by shaping the beauty that lies within. Nowadays, with the continuous development of university culture, the role of aesthetic education is no longer limited to the cultivation of individual emotions. It can also promote college students to discover and create beauty, and thus pursue self-improvement.

Quality education is proposed to complement the testoriented education that people often talk about. The testoriented education emphasizes the transmission of knowledge, but ignores the development of ability. Quality education is different from test-oriented education in that the former explores the potential of learners themselves, and teaches them to establish a correct outlook on life and values by imparting knowledge and technology. As a university student, it is necessary to associate himself with the reality, focus on practice, and develop in an all-round way. The author found in the campus life that college students around the author pay much attention to education aimed at cultivate self-quality. For example: they would like to have a high level of political awareness, be progressive in thinking, and care about the state affairs; Where they are leisure time, they would apply for a double degree to the school, and go to audit in classrooms of other majors; Through internships and participation in summer social practice, they accumulate social experience, laying a foundationn for an early entry into society. These are the weather vanes on campus, which shows that college students have some a strong desire for knowledge and self-value. They have a strong yearning for aesthetic education, which has prompted them to make efforts for a comprehensive development.

After understanding the connotations of aesthetic education and quality education, we need to further analyze their relationship, which is of great significance to what follows about our research. At the Third National Education Work Conference convened by the Party Central Committee and the State Council, university aesthetic education is included as an indispensable component in the implementation of quality education in colleges and universities. [1] This meeting raised the role of aesthetic quality in quality education to a new height In short, aesthetic quality is subordinate to quality education and is an indispensable aspect of quality education. At the same time, if the aesthetic education is incomplete, quality education is also imperfect. In summary, aesthetic education has a positive effect on the comprehensive implementation of quality education. 


\section{ROLE OF AESTHETIC EDUCATION IN THE DEVELOPMENT OF SCIENCE AND TECHNOLOGY COLLEGE STUDENTS}

Aesthetic education is conducive to shape a healthy personality. From the perspective of psychology, the so-called personality refers to the synthesis of various psychological characteristics. Personality is an independent force, and also a psychological process that presents us with an inherent way of thinking and behavior. Shaping a sound personality is one aspect in our ordinary life. If a college student has a low level of aesthetic education, it will result in an incomplete psychological structure, leading to the fragmentation of personality. Therefore, better aesthetic education is a psychological condition for perfect personality. In the beautiful ivory tower environment, a sound personality will be the foundation for the growth of science and technology college students. It is known to all that the current social competition is cruel, and students' academic pressure is high, and as a result, their mental pressure is increased sharply. They will become depressed and sullen, thinking that they are insignificant in society and even have no value at all. Consequently, they don't harbour any hope for future life, and come under enormous psychological pressure, leading to a sick state of mind. This series of negative energy can destroy at any time a college student who should have a bright future. In the current stage of education, there is no education system for a sound personality. At this time, it is necessary for aesthetic education to exert a catalytic effect, helping them find the lost beauty, constantly repairing their personality, and even making it sound, so that college students know to be proactive and work hard while they lose orientation. Some students in science and technology colleges and universities lack specific vocational ability planning and yearning. When they are in a low mood, and there is no corresponding release route, they will encounter psychological problems. As a catalyst, aesthetic education provides a shortcut for such students and can improve the personality psychology of science and technology students. [2]

Aesthetic education contributes to the development of individual thinking. Modern brain science research shows that the human brain accounts for about three-quarters of the whole brain, which is divided into left and right hemispheres. The left and right hemisphere each have their own duties and different divisions of labor. The left hemisphere of the human brain is a computational processing system responsible for language, logic, and mathematics, belonging to logical thinking; The right hemisphere is mainly a dialectical system responsible for music, art, and space knowledge, and it belongs to image thinking. The essence of giving play to the effective role of aesthetic education is to develop the right hemisphere of the human brain. The graceful dance is relaxing and pleasing, and the dance art is presented to the audience through body language and music. It is an interpretation of the dancer's attitude towards life. A person's creativity can be stimulated through this series of representations. Aesthetic education teaches us the appreciating ability of beauty and develop the skills of individual thinking. Science and technology Colleges students are mostly engaged in the study of mathematics and science, namely, they mainly use abstract thinking. Aesthetic education is based on image thinking. The improvement of science and Technology College students improve in aesthetic education is beneficial to develop their right brain, combine image thinking with abstract thinking, and perfect their way of thinking.

Aesthetic education is conducive to stimulate innovation. The reason why aesthetic education can stimulate creativity is that aesthetic education has special functions. In the aesthetic process, the aesthete perceives, associates, and imagines the aesthetic object. This series of psychological activities is intended to discover the driving force for newness. Students trained by science and technology colleges and universities are meticulous in thinking, rigorous in learning style and pragmatic, and they are the reserve echelon of talents in China. The improvement in the aesthetic education of science and technology college students can stimulate their innovative skills. When people's aesthetic quality reaches a certain level, they will have more active thinking and will be outstanding in their creative ability. The same applies to science and technology college students with poor aesthetic quality. When their aesthetic quality is improving, they will show a strong desire to create beauty and can discover novelties. It is precisely because the aesthetic quality of science and technology college students stimulates their innovation power and they have already had good professional qualities, they will become more excellent in various aspects. This type of ability optimization is attributed to the penetration of aesthetic education.

\section{STATUS QUO OF AESTHETIC EDUCATION OF SCIENCE AND TECHNOLOGY COLLEGE STUDENTS AND ITS CAUSES}

Against the background of an increasingly strong campus culture, aesthetic education has quietly come to us, but many science and technology colleges and universities still have some deficiencies in this aspect. This has pointed out the direction for our future work, and requires us to pay more attention to the issue of aesthetic education, and set up more reasonable pathways for aesthetic education. First, science and technology learners may lack in knowledge about aesthetic education theory. Some science and technology students are even unclear about its concepts. They believe that aesthetic education is just the art, music, and dance that they were exposed to during the primary and secondary school, and they think that these elective courses are boring, and are not to be included the future blueprint. College students have no time or even the need to cultivate this aspect of interest. It can be seen that such science and technology students have a certain misunderstanding of aesthetic education; second, some science and technology students have missed the aesthetic activities. Aesthetic education knowledge is imparted by educators imposing on the educated, nor is it measured by test scores. The four-year life at college can pass quickly, and the academic pressure is also enormous at the same time, causing more students to focus on the professional courses with final exams and the various certificates they strive to get for their career. Therefore, they have no energy to participate in the aesthetic activities, and miss the opportunity to improve themselves. Third, science and technology students pay less attention to aesthetic education. Science and technology students have a utilitarian learning motivation, and pay close attention to their future prospects. Therefore, they do not pay attention to the 
cultivation of aesthetic education. Over time, they will only be addicted to academics and become indifferent to other things. In the face of setbacks, they get into a pit fall, and have no better solution. However, aesthetic education is related to the spiritual life of college students and is one aspect that modern education should not underestimate.

The reasons why science and technology learners have a poor understanding of aesthetic education should be analyzed from both subjective and objective aspects. The subjective cause is that science and technology college students have misunderstandings about aesthetic education in their thought. They think that the professional knowledge they have learned in colleges is the only one that should be carefully studied, and others are not important. Or some science and technology college students focus on pursuing trends, and they like to be different, thinking that a college life should be colorful, they should dress up too differently, be addicted to video games, and get lost in love. They show a different look to some elegant art, thinking what they admire is elegance. It is difficult for some science and technology college students to calm down and discover the beauty around them, leading to no further improvement in aesthetic education. The objective cause is that it is a result of the complexities of the social environment and the imbalance of science and technology education initiatives. The university is equivalent to a small society. College students will be affected and influenced by social thoughts, because some interest problems become utilitarian, and their vanity drives them to obtain material benefits, and their spiritual civilization world is empty, which will lead to a series of phenomena for their weak aesthetic quality. University is the golden period of cultivating aesthetic education. China's science and technology colleges and universities neglect aesthetic education, which is really not good for science and technology learners. Modern quality education calls for aesthetic education, and aesthetic education has become popular for a while, which has already become an important trend in the theoretical research and reform of quality education in science and technology colleges and universities.

\section{SPECIFIC MEASURES TO STRENGTHEN THE AESTHETIC QUALITY OF SCIENCE AND TECHNOLOGY COLLEGE STUDENTS}

Aesthetic education courses should be offered. Colleges and universities should set up systematic aesthetic education theories and incorporate them into teaching programs, such as music appreciation, art appreciation, art appreciation, and aesthetic education principles. Special lectures should be given on aesthetic education, allowing science and technology learners to have a more realistic experience of aesthetic education. In recent years, there have been more and more courses concerning aesthetic quality in higher education institutions, which shows that the degree of emphasis has been improved. The provision of the aesthetic education courses has a positive effect, allowing science and technology students to discover and appreciate beauty. However, research shows that in higher education institutions, moral education, intellectual education, and physical education all have measurement standards and evaluation systems, and their grades are linked to graduation. There is no such provision on aesthetic education alone. It is hoped that while college and universities attach importance to aesthetic education, they can have certain measurement standards, as such a practice is conducive to mobilize the enthusiasm of science and technology college students in participating in aesthetic education. In addition, in the process of continuous development of aesthetic education, the author has a bold idea, that is, science and technology colleges and universities should list at least one aesthetic education course as a compulsory course.

Aesthetic education should be integrated into the teaching of science and technology. Aesthetic education needs to be infiltrated into various disciplines, so that science and technology learners can accept it subconsciouly, then it can be said that interdisciplinary and cross-boundary teaching practice is realized for aesthetic education. [3] Theoretical knowledge of aesthetic education should be combined with the majors of science and technology students, so that while students acquire professional knowledge, they generate interest in the profession. As a result, aesthetic education is embedded in all the courses. This measure not only aims at the mastery of the students, but also requires the guidance from the educators. In the process of imparting knowledge, teachers use subtle techniques to integrate the aesthetic education in their teaching. Teachers play a vital role, and need to exert their own personality charm. They should have higher standards in various aspects, pay attention to their own professional ethics and self-cultivation, dress up themselves with aesthetic education, and display the personality charm as a teacher in quality education. The efforts of educators and the self-development of the educated are inseparable. The aesthetic education should be implemented and an optimal combination should be realized to promote the improvement of quality education for science and engineering college students.

Meanwhile, a good campus culture environment should be created. The campus atmosphere is a very important factor. Imagine one walks into the campus. Students are enjoying the ancient poems, playing the piano, practising calligraphy, drawing pictures, and communicating English, etc. in threes and fours. Is such a lively scene a pleasant one? Campus culture is the best carrier for college students to cultivate aesthetic education. The basic environment of the university campus is also an important arena for aesthetic education in science and technology universities. The school should have some special places, so that science and technology students can appreciate the beauty after class. For example, they can discover the beauty while exploring the campus culture history in the school museum. Science and technology learners can also participate in some school organizations, such as student unions, societies, Family of Party Members, and so on. Through contact with different people and things, they can broaden their horizons, edify their emotions, and cultivate hobbies. 


\section{CONCLUSION}

Aesthetic education, as an indispensable part of quality education, plays an important role in the development of sound personality psychology and individual thinking, as well as in stimulating creativity, and cultivating sentiment. It takes ten years to grow a tree and a hundred years to bring up a generation of good men. Aesthetic quality education has a long way to go in science and technology colleges and universities. Society, school, and family should create a strong artistic aesthetic atmosphere for college students, so that they can be really involved in this atmosphere. College students should employ their own wisdom and make contributions to the society under the guidance of aesthetic education society.

\section{REFERENCES}

[1] Li Liang. A Brief Discussion the Effect of Aesthetic Education on College Students' Quality Education and Its Implementation Strategies[J]. Youthful Years, 2013(06): 208-208. (In Chinese)

[2] Gao Wei. Research on Status Quo and Countermeasures of Aesthetic Education in Science and Technology Universities [D]. Kunming University of Science and Technology, 2011. (In Chinese)

[3] Gong Qi. Impact of Aesthetic Education on College Students' Quality Education [D]. Shandong Normal University, 2009. (In Chinese)

[4] Ye Xin, Liu Ying. Analysis of the problems and countermeasures of public art education in science and engineering universities [J]. Art Education, 2015 (02): 97. (In Chinese)

[5] Qiu Di, Xie Zhaohui. Discussion on the Difficulties and Countermeasures of College Aesthetic Education[J]. Education Exploration, 2015(06): 87-90. (In Chinese)

[6] Zhang Dexiang, Lin Jie. Historical Review and Realistic Reflection of University Quality Education[J]. China Higher Education Research, 2017(06): 1-7+29. (In Chinese)

[7] Yi Lili. Analysis of the role of aesthetic education in quality education in colleges and universities[J]. Education Modernization, 2017, 4(25): 8283. (In Chinese) 